(Laboratory of Microbiology, Technical University, Delft, Holland).

\title{
SOME OBSERVATIONS ON AIR FILTRATION
}

by

\section{A. J. KLUYVER and J. VISSER}

(Received June 17, 1950).

\section{INTRODUCTION.}

As has already been remarked in our previous communication (1) the problem of the removal of germs from air currents is of ever increasing importance nowadays. It is well-known that the problem is usually solved by filtering the air through suitable materials. Nevertheless it appears that in industrial practice difficulties are not seldom encountered in this procedure, and therefore it seemed worth-while to collect some data regarding the factors which determine the success of the operation. Although the investigations reported here bear only a preliminary character, some of the results obtained may be of sufficient interest to justify their publication.

The more so, since the literature dealing with the subject is very scanty. The only publication known to us which brings some essential data regarding the filtration process is that of TERJESEN and CHERRY (2).

In this study special attention has been given to the suitability of a special type of slag wool ("Stillite") as a filtering medium. The favourable results obtained with this material induced us to include also "Stillite" in our experiments. On our request the "Stillite Products Ltd" 1) kindly put two small sample "Stillite" filter pads at our disposal. Besides this, cotton wool and carbon have been tested on their filtering properties.

\section{Methods and equipaent.}

In all experiments air was used which had been artificially contaminated with spores of Bacillus cereus applying the modified

1) Sardinia House, Kingsway, London WC 2. 
nebulizer described in our preceding communication (1). Hereto no use was made of the secondary air flow through the nebulizer. In the earlier experiments the air was sucked through a bottomless flask which had been filled with the filtering material. The filter as such had previously been subjected to a heat sterilisation at $160^{\circ} \mathrm{C}$. for one hour. After leaving the neck of the flask the air passed three capillary impingers in parallel arrangement. Each impinger contained as usually $80 . \mathrm{ml}$ of water. These impingers together with the comnecting tubes had also becn previously sterilized in the autoclave at $120^{\circ} \mathrm{C}$. for 15 minutes.

After the end of the experiment the water in the impingers was tested on the presence of germs either by mixing a suitable quantity of the water with melted nutrient agar, or by inoculating $5 \times 10 \mathrm{ml}$, $5 \times 1 \mathrm{ml}$ and $5 \times 0.1 \mathrm{ml}$ in tubes containing $10 \mathrm{ml}$ peptone water (1\% peptone, $0.5 \% \mathrm{NaCl}$ in tap water). After incubation for 16 hours at $37^{\circ} \mathrm{C}$. colonies on the plates were counted, and when use had been made of the tubes the latter were examined for growth. From the outcome of this examination the most probable number (M.N.P.) of bacteria present in the water sample was established with the aid of the table in use for the evaluation of coli tests in water examination (3).

It should be remarked here that in a later phase of our investigation we have made some determinations with both plate method and the liquid medium test. From these experiments it appeared that the first method always gave somewhat higher counts. Apparently a certain percentage of the spores of Bacillus cereus does not germinate in peptone water under the conditions prevailing in our experiments, whilst they do germinate on the nutrient agar plates.

For this reason some reserve must be made with regard to the absolute value of the results reported below; nevertheless it seems acceptable that the total picture is scarcely influenced by this imperfection of the liquid medium test.

In the first experiments the filter was tightly packed with cotton wool, great care being taken to avoid channeling. The results, however, were disappointing, in so far as never complete sterilization of the air was attained even with only moderately contaminated air.

It seemed probable that this unfavourable result would be due to air leakage occurring between the wall of the flask and the cotton wool. For this reason it was decided to improve the filter 
in such a way that the danger of edge leaking would be minimized. This led to a construction as reproduced in Fig. 1.

In the bottom of a metal cylinder a circular opening of $10 \mathrm{~cm}$ diameter was made and covered with copper gauze. To this bottom a metal funnel was fixed as indicated in Fig. 1. Into the cylinder a number of discs of cotton wool were brought which then were compressed by putting in a second closely fitting cylinder with broad flanges, also leaving a circular opening of $10 \mathrm{~cm}$ diameter. Then a second disc of cotton wool was pressed in the inner cylinder with the aid of another closely fitting cylinder with flanges, and this operation was repeated for a third time. The opening of the last cylinder was also covered with copper gauze. All the cylinders were then subjected to strong pressure so that the distance between two flanges was reduced to $9 \mathrm{~cm}$; they were then bolted together.

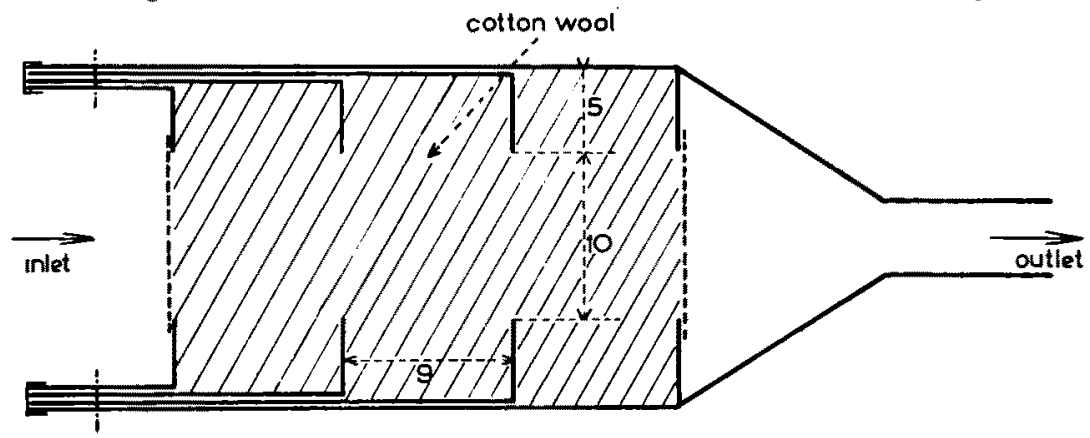

Fig. 1. Cotton wool filter.

In this way a strongly pressed cotton wool column of $27 \mathrm{~cm}$ thickness was obtained. It will be clear that leakage of air between cylinder wall and cotton wool can only occur in so far as the air twice passes between the wool and the flanges. Owing to the high pressure the air passage will here be much more difficult than between the wool and the cylinder wall. Moreover, since in each compartment the length of direct way of the air through the wool will be only $9 \mathrm{~cm}$ as compared with a length of $19 \mathrm{~cm}$ for the way of the air which passes between the wool and the wall, it is extremely improbable that any leakage will have occurred.

Since it was soon observed that the cotton wool lost a great deal of its elasticity, if the filter was subjected to a dry sterilisation, we have later always sterilized the filter in an autoclave at $120^{\circ} \mathrm{C}$. for 15 minutes. During this operation there was no mechanical pressure on the filter. 
For the stillite filter pads - each of which measured $30 \times 30 \times$ $5 \mathrm{~cm}$ - a special frame was constructed of which a sectional

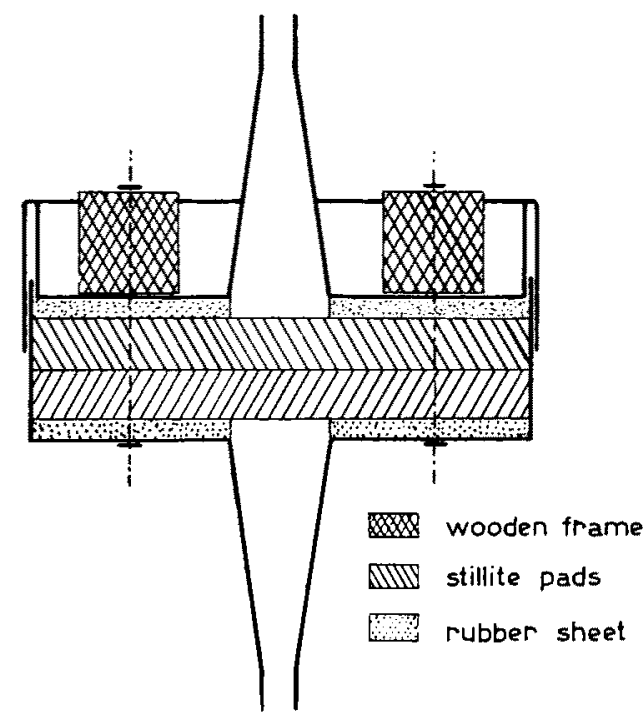

Fig. 2. Stillite filter. drawing is shown in Fig. 2.

The frame consists of two square metal boxes with conicalinlet and outlet for the air. In the inner box a rubber sheet with a circular opening of $10 \mathrm{~cm}$ diameter, is brought, and hereupon the two stillite pads rest. These were covered by another rubber sheet with a similar opening as the former. Then the outer box was put in the position as indicated in the figure. In this state the filter was sterilized in an autoclave at $120^{\circ} \mathrm{C}$. for 15 minutes. Then the boxes were pressed together with the aid of a metal frame bearing four screws. Hereby a wooden frame acted as a buffer.

For the filtration experiments with carbon we used simple metal cylinders of $15 \mathrm{~cm}$ diameter which were kept in a vertical position and through which the air passed in downward direction. At the bottom of the cylinder there was a copper gauze covered with glass beads, at the top of which another gauze acted as a support of the carbon. After some preliminary experiments the carbon "Norit PK 0.5-1 mm" proved to be the most suitable. The carbon filter was always subjected to a dry sterilisation at $160^{\circ} \mathrm{C}$. for one hour.

In experiments with low velocity the contaminated air was sucked through the sterilized filters and then passed three capillary impingers in parallel arrangement. In later experiments in which the velocity of the air was raised the limited capacity of the impingers did only allow the analysis of a fraction of the total flow which should be well kept in mind in considering the results obtained. In these cases we used an arrangement as indicated in Fig. 3.

For the main air flow use was made of an ordinary vacuum 
cleaner. In order to sample the air after its passage through the filter part of the air flow (9 litre/min.) was sucked through the three impingers with the aid of a vacuum pump. In each of the air flows the rate was determined with the aid of a flowrator of the FISHER and Porter Cy.



Fig. 3. Experimental scheme.

\section{Experiments with COTton wool as a Filter medium.}

A first series of experiments was made with air which was contaminated with about 800 spores per litre. Hereto we first determined the amount of spore suspension sprayed by the nebulizer during one hour. Some experiments had shown that, in accordance with observations of other workers, the number of germs present in the spray is as a rule only about $20 \%$ of that calculated on the amount of suspension which disappears from the nebulizer. In the calculation of the contamination we have, therefore, always applied an empirical factor of 0.2. Dependent on the air flow used in each experiment the concentration of the spores in the suspension was 
varied in such a way that always the approximate number of 800 per litre was obtained in the air flow which entered the filter.

It seems unnecessary to report here in detail all experiments made. In the beginning it was not rare to find that some spores had passed the filter and were retained in one or more of the impingers. It seems probable that this result was due to unsufficient care in the packing of the cotton wool in the filter.

When gradually more experience had been obtained in this operation these failures disappeared.

After this stage had been attained experiments were made to establish whether raising of the velocity of the air flow would affect the result. Such an experiment is reported in Table I.

It should be remarked once for all that the expression "maximum linear velocity" in the tables has only an arbitrary significance. The figures given are calculated on the basis of the diameter of the circular opening left by the flanges present in the filter whilst the space occupied by the filter material was left out of account. In reality the air velocity in the filter is, therefore, at certain spots markedly higher.

\section{Table I.}

Experiments on the influence of the relocity of the air flow on the efficiency of a cotton wool filter.

Number of spores in air before filtration: \pm 800 per litre; thickness cotton wool layer: $27 \mathrm{~cm}$; weight of cotton wool in filter: 900 gram; duration of each experiment: one hour.

\begin{tabular}{r|c|c|c|c|c}
\hline \hline $\begin{array}{c}\text { No of } \\
\text { exp. }\end{array}$ & $\begin{array}{c}\text { Vol. of air } \\
\text { passing in } \\
\text { litres/min. }\end{array}$ & $\begin{array}{c}\text { "Max.linear } \\
\text { velocity" of } \\
\text { air filter } \\
\text { in cm/sec. }\end{array}$ & $\begin{array}{c}\text { Total vol. of } \\
\text { filtered air } \\
\text { in litres }\end{array}$ & $\begin{array}{c}\text { M.P.N. of } \\
\text { spores re- } \\
\text { tained by } \\
\text { impingers }\end{array}$ & $\begin{array}{c}\text { M.P.N. of } \\
\text { spores pass- } \\
\text { ing the filter }\end{array}$ \\
\hline $37 \mathrm{a}$ & 9 & 2 & 540 & 0 & 0 \\
b & 20 & 4 & 1200 & 0 & 0 \\
c & 35 & 7 & 2100 & 0 & 0 \\
d & 51 & 11 & 3060 & 0 & 0 \\
e & 63 & 14 & 3780 & 0 & 0 \\
\hline
\end{tabular}

It appears from Table $I$ that an increase of the air velocity from 9 litre/min. to 63 litre/min. did not affect the satisfactory filtering action. Owing to the rather considerable resistance which the filter 
offers to the air passage, it was not feasible to attain a higher velocity with the equipment at our disposal.

It seemed worth-while to repeat these experiments with a more heavily contaminated air flow. This time the contamination was of the order of 10.000 spores per litre; slight variations in the individual experiments, however, being unavoidable. The results of this series of experiments are given in Table II.

Table II.

Experiments on the efficiency of a cotton wool filter using heavily contaminated air.

Number of spores in air before filtration: $\pm 2.10^{4}$ per litre; thickness cotton wool layer: $27 \mathrm{~cm}$; weight of cotton wool in filter: 830 gram.

\begin{tabular}{c|c|c|c|c|c|c}
\hline \hline & No of \\
exp. & $\begin{array}{c}\text { Duration } \\
\text { of exp. } \\
\text { in hours }\end{array}$ & $\begin{array}{c}\text { Vol. of air } \\
\text { passing in } \\
\text { litres/min. }\end{array}$ & $\begin{array}{c}\text { "Max.line- } \\
\text { ar veloci- } \\
\text { ty" of air } \\
\text { in filter } \\
\text { in cm/sec. }\end{array}$ & $\begin{array}{c}\text { Total vol. } \\
\text { of filtered } \\
\text { air in } \\
\text { litres }\end{array}$ & $\begin{array}{c}\text { M.P.N. of } \\
\text { spores re- } \\
\text { tained by } \\
\text { impingers }\end{array}$ & $\begin{array}{c}\text { M.P.N. of } \\
\text { spores } \\
\text { passing } \\
\text { the filter }\end{array}$ \\
\hline $50 a$ & $3 / 4$ & 9 & 2 & 405 & 2 & 2 \\
b & $3 / 4$ & 20 & 4 & 900 & 5 & 9 \\
c & $3 / 4$ & 35 & 7 & 1575 & 2 & 6 \\
d & $3 / 4$ & 49 & 10 & 2205 & 0 & 0 \\
e & $3 / 4$ & 59 & 12 & 2655 & 0 & 0 \\
f & $3 / 4$ & 100 & 21 & 4500 & 2 & 18 \\
\hline 53 & $101 / 3$ & 81 & 17 & 50220 & 5 & 43 \\
$5:$ & $1:$ & 68 & 14 & 44880 & 34 & 257 \\
\hline
\end{tabular}

It is noteworthy that in all cases the number of spores which were found to pass the filter is very low in proportion to the millions of spores which have been retained by the filter. This may account for the fact that in two of the experiments no spores were trapped in the impingers; obviously a chance factor also influences the result. There is no clear indication that the velocity of the air influences the result.

Nevertheless, the data of Table II, as compared with those of Table I, leave no doubt that a high degree of contamination of the unfiltered air presents a real danger for the success of the filtration operation. This conclusion seems to be warranted, although it 
should be taken into account that in this series the cotton wool was not as tightly packed as in the former series, as manifested by the higher velocity of air which could be attained.

The fact that in the first series of experiments reported in Table II the numbers of spores retained by the impingers were very low, made it seem desirable to test whether these results had real significance or that they were only due to imperfections in the technique used. For this reason also two experiments of longer duration were made, the results of which leave no doubt that indeed the filter did not remove all germs from the passing air.

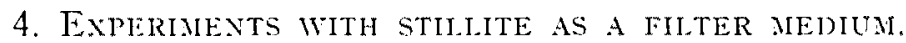

A microscopic cxamination of the stillite fibres revealed their extreme fincness. A comparison with cotton wool led to the following fisures:

$\begin{array}{lcc} & \begin{array}{c}\text { Variation } \\ \text { diam. in /" }\end{array} & \begin{array}{c}\text { Prevailing } \\ \text { diam. in " }\end{array} \\ \text { Stillite } & 2.5-25 & 2.5-10 \\ \text { Cotton wool } & 15-26 & 18-20\end{array}$

ior the experiments the stillite filter as described in section 2 has be en used.

The results of a series of experiments in which the air contami-

\section{Table III.}

Experiments on the influence of the velocity of the air flow on the efficiency of a stillite filter.

Number of spores in air before filtration: \pm 800 per litre; thickness stillite layer: $10 \mathrm{~cm}$; duration of each experiment: one hour.

\begin{tabular}{|c|c|c|c|c|c|}
\hline $\begin{array}{c}\text { No of } \\
\text { exp. }\end{array}$ & $\begin{array}{l}\text { Vol. of air } \\
\text { passing in } \\
\text { litres/min. }\end{array}$ & $\begin{array}{l}\text { "Max. incar } \\
\text { "clocity" of } \\
\text { air in filter } \\
\text { in } \mathrm{cm} / \mathrm{sec} \text {. }\end{array}$ & $\begin{array}{l}\text { Total vol. of } \\
\text { filtered air } \\
\text { in litres }\end{array}$ & $\begin{array}{l}\text { M.P.N. of } \\
\text { spores re- } \\
\text { tained by } \\
\text { impingers }\end{array}$ & $\begin{array}{l}\text { M.P.A. of } \\
\text { spores pass- } \\
\text { ing the filter }\end{array}$ \\
\hline $58 a$ & 9 & 2 & 540 & 0 & 0 \\
\hline$b$ & 20 & 4 & 1200 & 0 & 0 \\
\hline$c$ & 35 & 7 & 2100 & 0 & 0 \\
\hline d & 43 & 9 & 2580 & 2 & 10 \\
\hline $\mathrm{e}$ & 77 & 16 & 4620 & 2 & 17 \\
\hline f & 102 & 22 & 6120 & 0 & 0 \\
\hline$g$ & 125 & 27 & 7500 & 0 & 0 \\
\hline $\mathrm{h}$ & 153 & 32 & 9180 & 0 & 0 \\
\hline
\end{tabular}


nation was again reduced to about 800 spores per litre are reported in Table III. In this series another attempt was made to study the influence of the air velocity on the filtration efficiency.

On the whole the results obtained with the stillite filter are most satisfactory. However, in both experiments $58 \mathrm{~d}$ and $58 \mathrm{e}$ one of the 15 tubes containing $10 \mathrm{ml}$ of the impinger fluid led to a development of Bacillus cereus. The possibility cannot be excluded that in these cases we have be'n dealing with a stray infection. This seems the more likely because with higher velocities of the air flow no spores were detected in the impingers.

The most gratifying result of the experiments in question is undoubtedly the fact that the stillite pads combine a high filtration cfficiency with a low resistance to the passing air. This is clearly manifested by the high air velocities which could be attained with our limited resources, velocitics which are approaching those used in technical filter systems (linear velocity: $100 \mathrm{~cm} \mathrm{sec}$.).

We then decided to establish also for the stillite filter in how far a higher degree of contamination of the air wisuld influence the filtration effect (Table IV).

Table IV.

Experiments on the efficiency of a stillite filter using heavily contaminated air.

Number of spores in air before filtration: $\pm 2.10^{4}$ per litre; duration of each experiment: one hour.

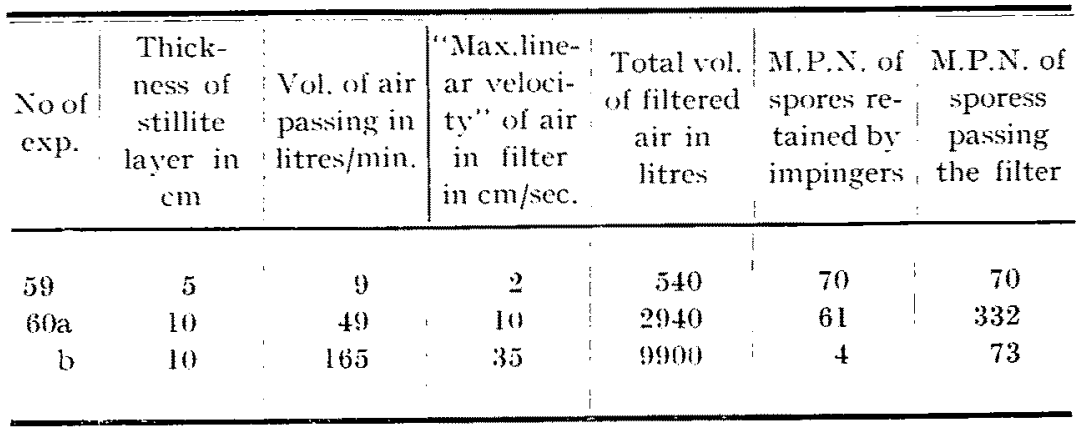

The results reported in Table IV show conclusively that for the stillite filter too there must be a critical degree of contamination which may not be surpassed without endangering the filtration effect. 
Using the only slightly contaminated laboratory air we have been able to establish that a stillite filter acts also very satisfactorily in an experiment of long duration. With an air volume of 153 litres/min. passing (linear velocity $32 \mathrm{~cm} / \mathrm{sec}$.) no germs were detected in the impingers even after 12 hours filtration.

\section{EXPERIMENTS WITH CARBON AS A FILTER MEDIUM.}

In all experiments reported in this section use has been made of Norit PK $0.5-1 \mathrm{~mm}$, this being a grade of carbon answering the requirement usually maintained for carbon used in technical air filtration operations, $i \mathrm{i}$., that of passing a sieve of 15 mesh (inch) and being retained by a sieve of 30 mesh (inch).

In the first series of experiments use was made of heavily contaminated air. Starting with a carbon column of $53 \mathrm{~cm}$ it was found that a good filtration effect was obtained. However, under these conditions the capacity of the filter was very low, and did not exceed 18 litres $/ \mathrm{min}$. (linear velocity $2 \mathrm{~cm} / \mathrm{sec}$.). For this reason

Table V.

The influence of the height of the carbon column on its filtration efficiency (heavily contaminated air).

Number of spores in air before filtration: $\pm 5.10^{4}$ per litre; duration of each experiment one hour, unless otherwise indicated.

\begin{tabular}{|c|c|c|c|c|c|c|}
\hline $\begin{array}{l}\text { No of } \\
\text { exp. }\end{array}$ & $\begin{array}{l}\text { Height of } \\
\text { carbon } \\
\text { column } \\
\text { in } \mathrm{cm}\end{array}$ & $\begin{array}{l}\text { Vol. of air } \\
\text { passing in } \\
\text { litres/min. }\end{array}$ & $\begin{array}{c}\text { "Max.line- } \\
\text { ar veloci- } \\
\text { ty" of air } \\
\text { in filter } \\
\text { in } \mathrm{cm} / \mathrm{sec} \text {. }\end{array}$ & $\begin{array}{l}\text { Total vol. } \\
\text { of filtered } \\
\text { air in } \\
\text { litres }\end{array}$ & $\begin{array}{l}\text { M.P.N. of } \\
\text { spores re- } \\
\text { tained by } \\
\text { impingers }\end{array}$ & $\begin{array}{l}\text { M.P.N. of } \\
\text { spores } \\
\text { passing } \\
\text { the filter }\end{array}$ \\
\hline 36 & 53 & 9 & 1 & 270 & 0 & 0 \\
\hline $39 a$ & 53 & 9 & 1 & 540 & 0 & 0 \\
\hline $\mathrm{b}$ & 53 & 18 & 2 & 1080 & 0 & 0 \\
\hline $\left.40^{1}\right)$ & 29 & 30 & 3 & 3600 & 0 & 0 \\
\hline 42 & 16 & 31 & 3 & 1860 & 0 & 0 \\
\hline $\left.44^{2}\right)$ & 16 & 37 & 4 & 5920 & 7 & 29 \\
\hline $47 a$ & 8 & 9 & 1 & 540 & 391 & 391 \\
\hline $\mathrm{b}$ & 8 & 20 & 2 & 1200 & 429 & 953 \\
\hline$c$ & 8 & 30 & 3 & 1800 & 555 & 1830 \\
\hline & & & & & & \\
\hline
\end{tabular}

1) Duration: 2 hours.

2) Duration: 2 hours 40 minutes. 
a series of experiments was made in which the height of the carbon column was gradually decreased. The results of these experiments are collected in Table $V$.

The figures in Table $\mathrm{V}$ show clearly that under the conditions of the experiment a column height of $16 \mathrm{~cm}$ presents more or less a critical value for the filter efficiency, in an experiment of longer duration the filter failed to retain all spores.

It seemed worth-while to check in how far with less contaminated air lower carbon columns - offering the advantage of higher filtration capacity - would prove to be acceptable from a filtration point of view. The results of these experiments are given in Table VI.

For each of the heights tested the highest velocity mentioned in the tables is the maximum which could be attained with the aid of our equipment.

Table VI.

The influence of the height of the carbon column on its filtration efficiency (moderately contaminated air).

Number of spores in air before filtration: \pm 800 per litre; duration of each experiment: one hour.

\begin{tabular}{|c|c|c|c|c|c|c|}
\hline $\begin{array}{l}\text { No of } \\
\text { exp. }\end{array}$ & $\begin{array}{l}\text { Height of } \\
\text { carbon } \\
\text { column } \\
\text { in } \mathrm{cm}\end{array}$ & $\begin{array}{l}\text { Vol. of air } \\
\text { passing in } \\
\text { litres/min. }\end{array}$ & $\begin{array}{l}\text { "Max.line- } \\
\text { ar veloci- } \\
\text { ty" of air } \\
\text { in filter } \\
\text { in } \mathrm{cm} / \mathrm{sec} \text {. }\end{array}$ & $\begin{array}{l}\text { Total vol. } \\
\text { of filtered } \\
\text { air in } \\
\text { litres }\end{array}$ & $\begin{array}{l}\text { M.P.N. of } \\
\text { spores re- } \\
\text { tained by } \\
\text { impingers }\end{array}$ & $\begin{array}{l}\text { M.P.N. of } \\
\text { spores } \\
\text { passing } \\
\text { the filter }\end{array}$ \\
\hline $52 a$ & 16 & 9 & 1 & 540 & 0 & 0 \\
\hline $\mathrm{b}$ & 16 & 20 & 2 & 1200 & 0 & 0 \\
\hline$c$ & 16 & 31 & 3 & 1860 & 0 & 0 \\
\hline $54 a$ & 11 & 9 & 1 & 540 & 0 & 0 \\
\hline $\mathrm{b}$ & 11 & 20 & 2 & 1200 & 0 & 0 \\
\hline c & $1 ?$ & 30 & 3 & 1800 & 0 & 0 \\
\hline d & 11 & 40 & +5 & 2400 & 0 & 0 \\
\hline $49 \mathrm{a}$ & 8 & 9 & 1 & 540 & 0 & 0 \\
\hline $\mathrm{b}$ & 8 & 20 & 2 & 1200 & 0 & 0 \\
\hline c & 8 & 32 & 35 & 1920 & 0 & 0 \\
\hline $\mathrm{d}$ & s & 37 & 4 & 2220 & 0 & 0 \\
\hline 5 la & 8 & 9 & 1 & 540 & 22 & 22 \\
\hline b & 8 & 20 & 2 & 1200 & 42 & 93 \\
\hline c & 8 & 30 & 3 & 1800 & 35 & 117 \\
\hline $\mathrm{d}$ & 8 & 40 & 4.5 & 2400 & 50 & 222 \\
\hline e & 8 & 51 & 6 & 3060 & 60 & 340 \\
\hline
\end{tabular}


If we compare the results presented in Table $V$ and Table VI we may conclude that the filtration effect is, indeed, dependent on the degree of contamination of the air to be filtered. We see further that under the changed conditions a. height of $8 \mathrm{~cm}$ is more or less a critical value: in the experiments 49 a-d still a satisfactory filtration took place, but in the experiments $51 \mathrm{a}-\mathrm{e}$, in which apparently the carbon column was somewhat less compact - as judged by the higher maximum velocity - the filter allowed many spores to pass. The latter experiments also show that the most probable number of spores which pass the filter increases with increasing velocity of the air; in first approximation in all cases a constant number of spores is carried by a certain volume of air. Such a simple relation has not been encountered in the cotton wool and stillite experiments.

It scems justified to conclude from all experiments made that carbon presents a very efficient filter medium, but has the disadvantage of a relatively low filter capacity por unit of filter surface. It should, however, not be lost sight of that this disadvantage is not of an absolute character: it can be counterbalanced either by increasing the filter surface or by raising the pressure of the inlet air.

In a final experiment we have attempted to get some insight into the depth in which spores penctrated into the carbon column.

Through a carbon column of $16 \mathrm{~cm}$ height air contaminated with 10.000 spores per litre was sucked with a velocity of 56 litres min. The experiment was continued for one hour; the analysis of the three impingers which were connected during the experiment showed that the air which passed the filter did not contain any spores.

After the experiment was ended a standardized sample was aseptically taken from the carbon column at various depths. This was accomplished by sucking away after each sampling a layer of $2 \mathrm{~cm}$ of the carbon with the aid of the vacuum cleaner. Each sample was brought into a sterile test tube containing $5 \mathrm{ml}$ of sterile water and the tubes were then eracuated in order to remove the air.

After thorough shaking the numbers of the bacteria present in the carbon suspensions were determined with the aid of the plate method; dilutions being made where necessary.

Although no absolute value can be attributed to the figures obtained, they still give a good idea of the distribution of the spores retained in the filter column. 


$\begin{array}{cc}\text { Depths in carbon column } & \text { Xumber of spores } \\ 0 & 118.000 \\ 2 & 9.500 \\ 4 & 218 \\ 6 & 0 \\ 8 & 0 \\ 10 & 0 \\ 12 & 0 \\ 14 & 0\end{array}$

In this experiment the spores had apparently not yet reached a depth of $6 \mathrm{~cm}$; this value is in fair agreement with our earlier experiment 47 in which a carbon column of $8 \mathrm{~cm}$ just failed to retain all spores.

\section{Sum mary.}

1. A method has been developed for testing the filtration efficiency of some filter materials. For each of the materials investigated - cotton wool, stillite and carbon - a suitable filter has been derised.

2. The filtered air was analyzed as to its germ content with the aid of a set of 3 capillary impingers.

3. The cotton wool filter gave on the whole satisfactory results provided that due attention was given to the packing of the filter and its sterilisation. Clear indications were obtained that the degree of the contamination of the air was of vital importarice.

4. The stillite filter proved to have the advantage of combining a high filtration efficiency with a low resistance to the passing air. Also for the stillite filter a critical degree of contamination of the air was established; on surpassing this degree the filtration effect was endangered.

5. The carbon filter proved to be most efficient, but had a relatively low specific filtering capacity. It was found that the filtration result was depending on the height of the carbon column and on the velocity and the degree of contamination of the air.

6. It should be stressed that in all experiments artificially contaminated air was used, and that the number of germs present in the air to be filtered was in all cases many times larger than that usually occurring in normal air.

The authors wish to express their sincere thanks to the ,Delftse Hogeschoolfonds" for the grant which has enabled them to carry out this investigation. 
References.

1. A. J. Kiluyver and J. Visser, The determination of micro-organisms in air. Antonie van Leeuwenhoek 16, 299, 1950. - 2. S. G. TERJESEN and G. B. ChERRY, The removal of micro-organisms from air by filtration. Trans. Inst. Chem. Eng. North Western Branch, Manchester, October 1947. - 3. Standard Methods for the Examination of Water and Sewage. New York, 9th Ed., 1946, p. 205. 